\title{
Low expression levels of plasma miR-141 are associated with susceptibility to gastric cancer
}

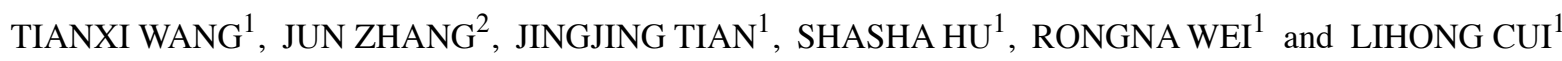 \\ ${ }^{1}$ Department of Gastroenterology, Tianjin Nankai Hospital, Nankai, Tianjin 300100; \\ ${ }^{2}$ Department of General Medicine, Tianjin Beichen Hospital, Tianjin, 300401, P.R. China
}

Received May 10, 2018; Accepted April 17, 2019

DOI: $10.3892 / \mathrm{ol} .2019 .10390$

\begin{abstract}
MicroRNAs (miRNAs/miRs) offer great potential as biomarkers for the early detection and prognosis of cancer, and the discovery of miRNAs associated with gastric cancer is required. In the present study, the differences in the plasma expression levels of miR-141 between patients with gastric cancer and healthy controls, and the role of miR-141 in gastric cancer cell oncogenesis were investigated. A follow-up study of 164 patients with gastric cancer who underwent tumor resection was conducted, and comparisons with healthy control subjects were drawn. To investigate the biological functions of miR-141, a series of in vitro and in vivo assays were conducted, including proliferation, wound-healing and Transwell assays, and a xenograft tumor model. The results demonstrated that miR-141 expression was significantly decreased in tumor tissues compared with in healthy tissues $(\mathrm{P}<0.05)$. Kaplan-Meier analysis revealed improved survival benefits with increased miR-141 expression (as determined using the log-rank test, $\mathrm{P}<0.001$ ), and multivariate Cox regression analysis revealed that patients with decreased expression levels of miR-141 carried a greater risk of death (hazard ratio $=2.352 ; 95 \% \mathrm{CI}=1.379-4.012 ; \mathrm{P}=0.002$ ). The downregulation of miR-141 was also associated with WHO staging, particularly for lymph node and distant metastasis. Exogenous overexpression of miR-141 significantly inhibited the proliferative and migratory abilities of the gastric cancer cell line $\mathrm{BGC}-823$. In vivo studies also demonstrated that exogenous overexpression of miR-141 in BGC-823 cells markedly reduced tumor growth in nude mice. The present study revealed that increased miR-141 expression may be a positive prognostic factor, which may be clinically beneficial in patients with gastric cancer.
\end{abstract}

Correspondence to: Professor Lihong Cui, Department of Gastroenterology, Tianjin Nankai Hospital, 122 Three Wei Road, Nankai, Tianjin 300100, P.R. China

E-mail: cuilihong1980@163.com

Key words: miR-141, gastric cancer, Kaplan-Meier analysis, WHO staging, multivariate Cox regression

\section{Introduction}

Gastric cancer is considered to be the fourth leading cause of cancer-associated mortality worldwide $(1,2)$, this is due partially to late diagnosis coupled with disease recurrence and chemoresistance. Therefore, the discovery of predictive markers for early detection and prognostic markers to optimize treatment is necessary $(3,4)$. MicroRNAs (miRNAs/miRs) are endogenous, non-coding RNA molecules in eukaryotes, 21-25 nucleotides in length $(5,6)$. Being present in various animal and plant cells, miRNAs serve important roles in a number of biological processes in humans, including development, cell proliferation and differentiation, apoptosis, angiogenesis and tumor growth. miRNAs act primarily by regulating signaling-associated molecules, including proliferation factors, pro-apoptotic and anti-apoptotic genes (7-9).

miRNAs are highly evolutionarily conserved, and their expression is time-dependent and tissue-specific $(10,11)$. miRNA mutations may potentially result in gene mutations and functional disorder, thus potentially inducing disease, including numerous types of cancer $(12,13)$. In oncology, the abnormal expression of miRNAs serves a noteworthy role in the proliferation, differentiation, apoptosis, migration and invasion of tumor cells, and miRNAs serve dual roles in tumor suppression and carcinogenesis $(14,15)$. In addition, miRNAs have been associated with the occurrence and progression of numerous tumor types $(16,17)$.

The convenient detection of early diagnostic markers has been a long-term aspiration for tumor screening and diagnosis. In previous decades, miRNAs have been widely studied as potential tumor markers due to their key roles in carcinogenesis. However, miRNA detection has primarily relied on tumor tissues obtained by surgery and biopsy, which has restricted their application as tumor markers. Previous studies have indicated that mature miRNAs are secreted from tumor tissues and exist stably in the peripheral blood $(18,19)$, which provides a convenient and potential source for the screening of miRNAs.

miR-141 is a member of the miR-200 family, which is associated with the formation of cancer stem cells and the regulation of epithelial-mesenchymal transition (20). Although miR-141 has been closely associated with the development of numerous types of cancer, including colorectal (21), ovarian (22) and gastric cancer (23), the association between miR-141 and 
gastric cancer lacks in-depth study. miR-141 modulates cisplatin sensitivity in gastric cancer cells by attenuating the functions of programmed cell death protein 4; therefore, the upregulation of miR-141 may be a novel therapeutic strategy for reducing the chemoresistance of gastric cancer cells (24). Inhibiting the functions of miR-141 suppresses gastric cell proliferation and increases caspase-3 activity in H1299 and docetaxel-treated H2009 cells (25). However, these studies focused on miR-141 expression from resected tumor tissue or cancer cell lines, and did not investigate expression levels in patient plasma (26). In the present study, miR-141 expression levels were detected in the peripheral plasma of patients with gastric cancer. The potential roles of miR-141 in gastric cancer pathogenesis, including grade, metastasis, prognosis and survival were also investigated.

\section{Patients and methods}

Study subjects. A total of 164 patients with gastric cancer who underwent tumor resection between January 2010 and December 2017 at the Tianjin Nankai Hospital (Nankai, China) were enrolled. The patient age range was 18-70 years with 93 male and 71 female subjects, and a median age of 56 years. The inclusion criteria were as follows: i) Confirmation of gastric cancer by pathological identification; Exclusion criteria were as follows: i) Gastrointestinal tract complications; ii) hemolysis; and iii) high blood lipid concentration (a plasma triglyceride concentration $>150 \mathrm{mg} / \mathrm{dl}$ or hypercholesterolemia $>200 \mathrm{mg} / \mathrm{dl}$ ). Peripheral blood plasma and tissue samples were obtained from each patient. The tissue specimens collected were fixed in $10 \%$ formaldehyde at $4^{\circ} \mathrm{C}$ overnight, embedded in paraffin and cut into $1 \mathrm{~cm}$ sections for pathological diagnosis. All diagnoses were confirmed based on histopathological examination, and histological grade was determined according to the criteria formulated by the World Health Organization (WHO; 2007) (27). Patient follow-up was conducted at 3-month intervals until December 31, 2017. A total of 109 healthy patients with a similar age and sex distribution were enrolled as controls. The present study was approved by the Tianjin Nankai Hospital Ethics Committee, and written informed consent was obtained from each subject.

RNA isolation and miR-141 quantification. Total plasma RNA was isolated from patients and healthy subjects using TRIzol $^{\circledR}$ reagent (Invitrogen; Thermo Fisher Scientific, Inc., Waltham, MA, USA) according to the manufacturer's protocol. Reverse transcription-quantitative polymerase chain reaction (RT-qPCR) was used to assess the expression levels of miR-141 in each group. Total RNA (250 ng) from each sample was reverse transcribed using single strand reverse transcription (SuperScript III First-Strand Synthesis SuperMix; Invitrogen; Thermo Fisher Scientific, Inc.) according to the manufacturer's protocol. TaqMan PCR assay kits were purchased from Applied Biosystems (Thermo Fisher Scientific, Inc.), and the primer sequences were as follows: miR-141, forward, 5'-GTC CATCTTCCAGTACAGTGTTG-3' and reverse, 5'-AGCCAT CTTTACCAGACAGTGT-3'; and RNU6, forward, 5'-GCT TGCTTCAGCAGCACATA-3' and reverse, 5'-AAAAAC ATGGAACTCTTCACG-3'. The relative expression levels of miR-141 were determined using the $2^{-\Delta \Delta \mathrm{Cq}}$ method (28). The thermocycling conditions were as follows: One cycle at $95^{\circ} \mathrm{C}$ for $30 \mathrm{sec}$, followed by 40 cycles at $95^{\circ} \mathrm{C}$ for $15 \mathrm{sec}, 60^{\circ} \mathrm{C}$ for $30 \mathrm{sec}$ and $72^{\circ} \mathrm{C}$ for $30 \mathrm{sec}$; the final extension was conducted for $5 \mathrm{~min}$ at $72^{\circ} \mathrm{C}$, prior to a temperature decrease to $4^{\circ} \mathrm{C}$.

Cell culture and miR-141 transfection. The gastric cancer cell line BGC-823 was purchased from the American Type Culture Collection (Manassas, VA, USA). Cells were cultured in RPMI-1640 medium (Gibco; Thermo Fisher Scientific, Inc.) supplemented with $10 \%$ fetal bovine serum (Gibco; Thermo Fisher Scientific, Inc.) and incubated at $37^{\circ} \mathrm{C}$ in an atmosphere containing $5 \% \mathrm{CO}_{2}$. miR-141 mimics were synthesized by Gene Company, Ltd. (Hong Kong, China), and the negative control (NC) RNA duplex was non-homologous to any human genome sequence. The miR-141 mimic sequence was 5'-ACA AAGUUCUGUGAUGCACUGA-3' a 2'-O-methyl-modified oligoribonucleotide, and the NC sequence was 5'-CAGUAC UUUUGUGUAGUACAA-3'. Cells $\left(1 \times 10^{6}\right.$ per well in a six-well plate) were transfected with RNA mimics $(50 \mathrm{nM})$ and NCs, using Lipofectamine ${ }^{\circledR} 2000$ reagent (Invitrogen; Thermo Fisher Scientific, Inc.) according to the manufacturer's protocol. Transfection efficiency was determined using western blotting and RT-qPCR.

Cell proliferation assay.Cell proliferation was assessed using an MTT assay. A total of $24 \mathrm{~h}$ post-transfection, $\sim 8 \times 10^{3}$ cells/well were seeded into 96 -well culture plates and incubated for a further $24,48,72,96,122$ and $146 \mathrm{~h}$. Subsequently, $20 \mu \mathrm{l}$ MTT $(5 \mathrm{mg} / \mathrm{ml})$ was added to the cells for $4 \mathrm{~h}$ at $37^{\circ} \mathrm{C}$, and the formazan crystals were solubilized using $150 \mu \mathrm{l}$ DMSO for $20 \mathrm{~min}$ at room temperature. The optical density was measured using a spectrophotometer (Multiskan MK3; Thermo Fisher Scientific, Inc.) at a wavelength of $490 \mathrm{~nm}(29)$.

Wound-healing assay. The migratory ability of cells was determined using a wound-healing assay. Briefly, $2 \times 10^{4}$ cells were inoculated in $6-\mathrm{cm}$ tissue culture dishes and cultured overnight. The cell monolayer was scratched when the cells reached $>90 \%$ confluence. Migration images were captured at $0,8,16$ and $24 \mathrm{~h}$, and the migration rate (gap closure, $\mathrm{mm}$ ) of cells was calculated.

Transwell migration assay. A $100-\mu 1$ cell suspension $\left(5 \times 10^{5} / \mathrm{ml}\right.$ in RPMI-1640 without FBS) was added to the upper chamber (pore size, $8 \mu \mathrm{m}$ ) of a Transwell system, and $600 \mu 1$ medium containing $10 \%$ FBS was added to the lower chamber. After $6 \mathrm{~h}$, the medium in the chamber was disposed of and unmigrated cells were removed. Cells were fixed with $4 \%$ paraformaldehyde for $10 \mathrm{~min}$, and subsequently stained with crystal violet for a further $10 \mathrm{~min}$ at $4^{\circ} \mathrm{C}$. The filter membrane was sealed with neutral gum, and images were captured using an inverted light microscope (magnification, x200). Cells were counted using Image-Pro Plus Version 6 (Media Cybernetics, Inc., Rockville, MD, USA); three wells in each group and five visual fields of each well were randomly selected, and the average cell number was determined.

Tumorigenicity assays in nude mice. A total of 21 female nude mice (BALB/C, nu/nu, 15-18 g) were purchased from the Institute of Laboratory Animal Sciences, Chinese Academy 
of Medical Sciences (Beijing, China) and housed in a laminar air-flow cabinet under specific pathogen free conditions; the mice were maintained at $20-22^{\circ} \mathrm{C}$ with $40-60 \%$ relative humidity and a 12-h light/dark cycle. Furthermore, the animals were provided with food and water ad libitum. Female BALB/c athymic nude mice (age, 6 weeks) were subcutaneously injected with $1.5 \times 10^{6}$ cells in $0.2 \mathrm{ml}$ PBS into the right armpit region. The following were administered to three separate groups of mice ( $n=7 /$ group); i) Group 1, BGC-823 cells transfected with miR-141 mimics; ii) group 2, BGC-823 cells transfected with NC RNA; and iii) group 3, untransfected BGC-823 cells. Tumor sizes were measured every 5 days using calipers, and tumor volumes were calculated using the following formula: [length $(\mathrm{mm}) \mathrm{x}$ width $\left.(\mathrm{mm})^{2}\right] / 2$. When the tumor with the largest diameter reached $15 \mathrm{~mm}$ in 4 weeks, the mice were euthanized with an intraperitoneal injection of pentobarbital sodium $(250 \mathrm{mg} / \mathrm{kg})$, and the tumor weights were determined. All animal experiments were approved by the Ethics Committee of Laboratory Animals of Tianjin Nankai Hospital (approval no. 00000531). The Guide for the Care and Use of Laboratory Animals (NIH publication no. 80-23, revised 1996) (30) and the institutional ethical guidelines for animal experiments were used as guides for all animal experiments. Animal health and behavior were monitored daily. To confirm that xenograft tumors expressed higher levels of miR-141 following the administration of miR-141 mimics, total RNA was extracted from tumor tissues and miR-141 levels were quantified using RT-qPCR.

Statistical analysis. Data are presented as the mean \pm standard deviation, and all experiments were repeated $\geq 3$ times. Statistical analyses were conducted using SPSS 19.0 software (IBMCorp.,Armonk,NY,USA). The Wilcoxon-Mann-Whitney test was used to compare the miR-141 expression levels between patients with gastric cancer and healthy controls. To investigate the association between miR-141 expression status and clinical-pathological characteristics, $\chi^{2}$ test was used. Kaplan-Meier analysis was used to measure survival analysis, and comparison of overall survival between two groups was performed using the log-rank test. The hazard ratio (HR) of each covariate was measured using multivariate Cox regression analysis. For the comparison of biological characteristics among untransfected, NC and miR-141 transfected cells, the data were analyzed using one-way analysis of variance, followed by the Bonferroni test. $\mathrm{P}<0.05$ was considered to indicate a statistically significant difference.

\section{Results}

Plasma miR-141 expression level is decreased in patients with gastric cancer. The plasma expression levels of miR-141 were compared between 109 healthy controls and patients with gastric cancer. As shown in Fig. 1, plasma miR-141 levels were significantly higher in the blood of healthy subjects compared with in patients with gastric cancer $(\mathrm{P}<0.01)$.

Association between miR-141 expression and clinicopathological characteristics. Patients were categorized into low- and high miR-141 expression groups, with the median value set as the cutoff. A total of 115 patients were categorized as having

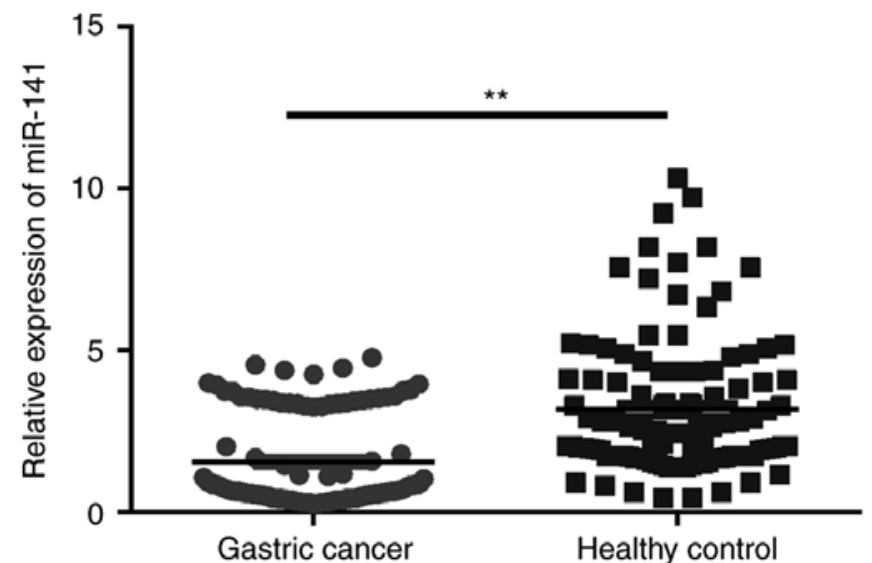

Figure 1. Plasma miR-141 expression profiles of patients with gastric cancer and healthy controls. ${ }^{* *} \mathrm{P}<0.01$. miR-141, microRNA-141.

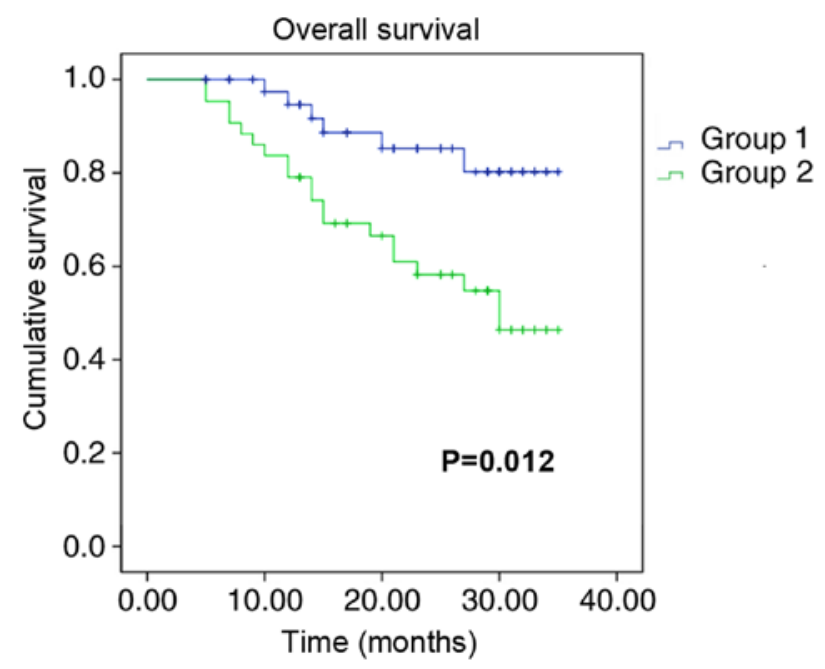

Figure 2. Kaplan-Meier survival analysis of miR-141 expression and overall survival in patients with gastric cancer. The blue line refers to patients with higher expression levels of miR-141, and the green line refers to those with lower expression levels of miR-141. miR-141, microRNA-141.

low expression, whereas 49 patients were identified as having high expression. It was demonstrated that miR-141 expression was not associated with age, tumor size, tumor location, resection range or adjuvant therapy. However, a significant association was observed between miR-141 expression and WHO grade (grade I+II vs. grade III+IV), recurrence time and overall survival time (Table I). As grades III and IV refer to lymph node and distant metastasis, respectively, the significant association for WHO grade also suggests that a lower miR-141 expression level may increase the risk of lymph node and distant metastasis in gastric cancer.

miR-141 expression level is associated with the overall survival of patients with gastric cancer. Kaplan-Meier survival analysis was performed to determine whether miR-141 expression was associated with the survival of patients with gastric cancer. Due to the loss of patients, follow-up was not conducted for seven of the original recruits. Patients with high expression levels of miR-141 exhibited greater overall survival times compared with 
Table I. Association between miR-141 expression and clinicopathological characteristics.

\begin{tabular}{|c|c|c|c|c|}
\hline \multirow[b]{2}{*}{ Clinicopthological characteristics } & \multirow[b]{2}{*}{ Patients, $\mathrm{n}$} & \multicolumn{2}{|c|}{ miR-141 expression level, $\mathrm{n}$} & \multirow[b]{2}{*}{ P-value } \\
\hline & & Low & High & \\
\hline Age (years) & & & & 0.058 \\
\hline$<60$ & 94 & 58 & 36 & \\
\hline$\geq 60$ & 70 & 53 & 17 & \\
\hline Tumor size & & & & 0.349 \\
\hline$<3 \mathrm{~cm}$ & 89 & 58 & 31 & \\
\hline$\geq 3 \mathrm{~cm}$ & 75 & 54 & 21 & \\
\hline World Health Organization grade & & & & 0.075 \\
\hline I & 17 & 7 & 10 & \\
\hline II & 76 & 47 & 29 & \\
\hline III & 52 & 39 & 13 & \\
\hline IV & 19 & 13 & 6 & \\
\hline I+II & & 54 & 39 & 0.049 \\
\hline III+IV & & 52 & 19 & \\
\hline Resection range & & & & 0.644 \\
\hline Total resection & 71 & 49 & 22 & \\
\hline Local resection & 93 & 61 & 32 & \\
\hline Adjuvant therapy & & & & 0.971 \\
\hline Radiotherapy & 13 & 9 & 4 & \\
\hline Chemotherapy & 35 & 23 & 12 & \\
\hline Radiotherapy and chemotherapy & 46 & 31 & 15 & \\
\hline Recurrence time & & & & $<0.0001$ \\
\hline$<3$ months & 96 & 77 & 19 & \\
\hline$\geq 3$ months & 68 & 33 & 35 & \\
\hline \multicolumn{5}{|l|}{ Survival duration } \\
\hline$<15$ months & 96 & 72 & 24 & 0.002 \\
\hline$\geq 15$ months & 68 & 35 & 33 & \\
\hline
\end{tabular}

miR-141, microRNA-141.

patients with low miR-141 expression levels (Fig. 2). The HR associated with miR-141 low expression was 2.352 (Table II). These data indicated that the aggressiveness of gastric cancer was associated with decreased expression levels of miR-141.

miR-141 inhibits cell proliferation and migration in vitro. Following the observation that miR-141 expression was significantly downregulated in gastric cancer samples, the functional role of miR-141 in the development of gastric cancer was investigated. Exogenous expression of miR-141 was significantly increased in miR-141-transfected BGC-823 cells compared with in untransfected and BGC-823-NC cells (Fig. 3A). The MTT assay revelaed that the proliferative ability of BGC-823-miR-141 cells was significantly decreased, compared with that of the control cell groups (Fig. 3B). Furthermore, the migratory ability of BGC-823-miR-141 cells, as determined using wound-healing (Fig. 3C) and Transwell assays(Fig. 4), was significantly decreased $(\mathrm{P}<0.05)$ compared with in the control cell groups. These results suggested that miR-141 may serve a key role in the proliferation and migration of gastric cancer cells.
miR-141 suppresses gastric cancer tumorigenicity in vivo. In order to validate the aforementioned results, in vivo experimentation was performed; untransfected BGC-823 cells, and those transfected with miR-141 mimics or NC were inoculated into three separate groups of mice. After 4 weeks, the BGC-823-miR-141 mimic group exhibited significantly decreased tumor growth and weight compared with the control groups (Fig. 5A-C). Furthmore, RT-qPCR analysis confirmed that miR-141 expression levels in tumor tissues derived from BGC-823-miR-141 mimics were significantly higher compared with in the other two groups (Fig. 5D).

\section{Discussion}

In the present study, the prognostic value of miR-141 in patients with gastric cancer was evaluated. It was revealed that plasma miR-141 expression levels in patients with gastric cancer were significantly lower compared with those in healthy control subjects. This is in contrast to miR-141 expression in gastric cancer tissues, in which a previous study suggested higher miR-141 expression levels in 
Table II. Multivariate Cox regression analysis of risk factors associated with the overall survival of patients with cancer gastric.

\begin{tabular}{lccr}
\hline Clinical characteristics & Hazard ratio & 95\% confidence interval & P-value \\
\hline Age & 1.005 & $0.978-1.032$ & 0.719 \\
Tumor size & 0.678 & $0.422-1.088$ & 0.014 \\
World Health Organization grade & 0.709 & $0.435-1.158$ & 0.001 \\
Resection range & 0.980 & $0.620-1.547$ & 0.930 \\
Adjuvant therapy & 0.934 & $0.576-1.516$ & 0.784 \\
Low microRNA-141 expression & 2.352 & $1.379-4.012$ & 0.002 \\
\hline
\end{tabular}

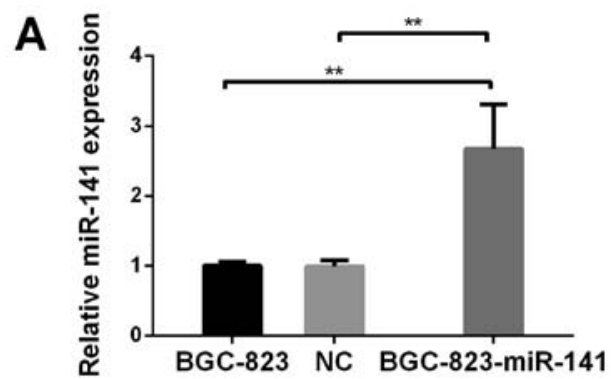

C
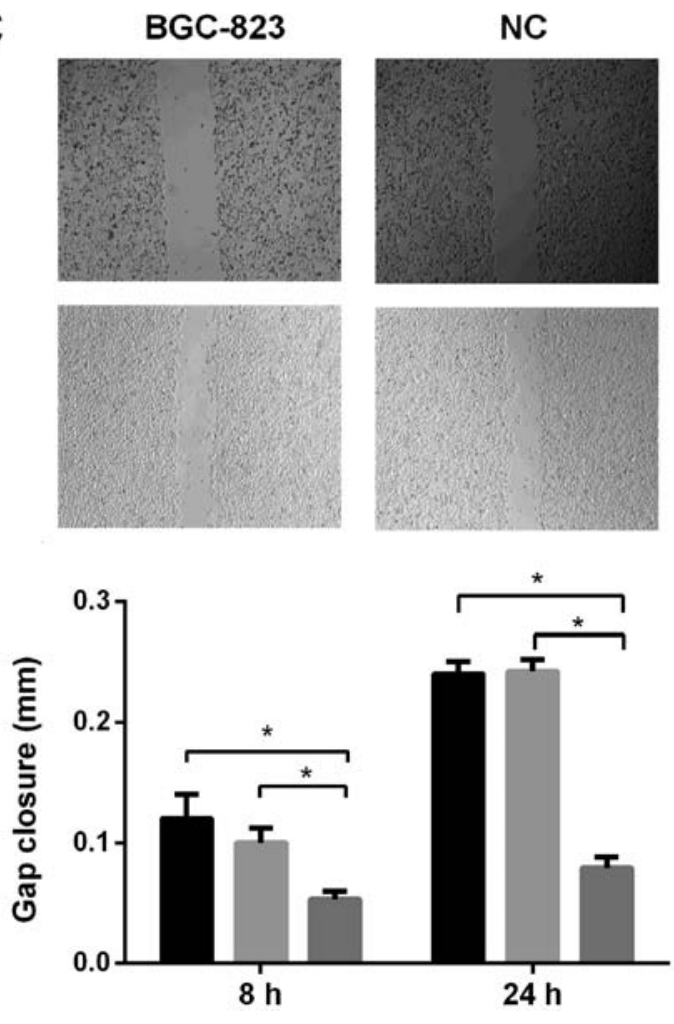

BGC-823-miR-141

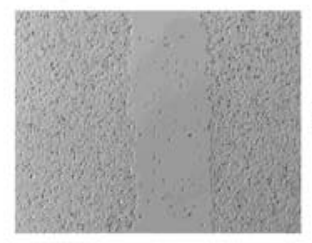

$8 \mathrm{~h}$
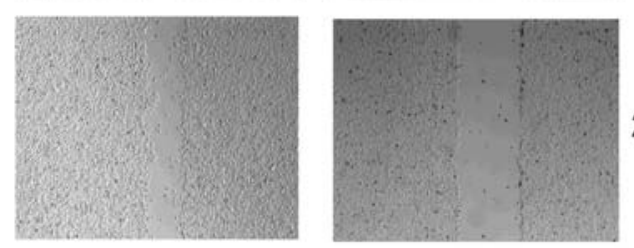

$24 \mathrm{~h}$

Figure 3. miR-141 inhibits cell proliferation in vitro. (A) Comparison of miR-141 expression levels among untransfected BGC-823, BGC-823-NC and BGC-823-miR-141 cells, as determined using reverse transcription-quantitative polymerase chain reaction. (B) MTT proliferation assay among untransfected BGC-823, BGC-823-NC and BGC-823-miR-141 cells. (C) Migration of BGC-823 cells was significantly reduced by miR-141 exogenous expression, as determined using a wound-healing assay (magnification, $\mathrm{x} 200$ ). ${ }^{*} \mathrm{P}<0.05,{ }^{* *} \mathrm{P}<0.01$. miR-141, microRNA-141; NC, negative control.

gastric cancer tissues compared with in healthy subjects (26). Patients with lower expression levels of miR-141 were revealed to have poor clinical outcomes, which supports the hypothesis that miR-141 serves a key role in the survival of patients with gastric cancer. Therefore, miR-141 expression may be used as an independent prognostic indicator of gastric cancer.
miRNAs are implicated as key regulators of normal cell function $(31,32)$, and their aberrant expression is associated with various diseases, including gastric cancer. A number of miRNAs have been associated with multiple regulatory networks in gastric cancer pathogenesis. It has previously been reported that miR-218 serves as a tumor suppressor regulating 

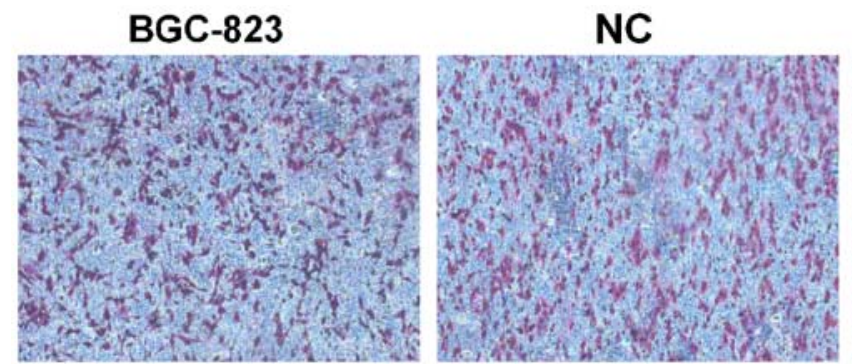

BGC-823-miR-141

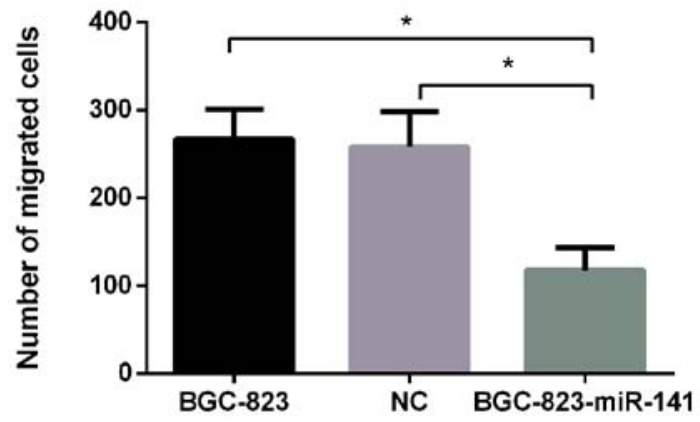

BGC-823

NC

BGC-823-miR-141

Figure 4. Comparison of the migration of untransfected BGC-823, BGC-823-NC and BGC-823-miR-141 cells using a Transwell assay (magnification, $\mathrm{x} 400$ ). "P<0.05. miR-141, microRNA-141; NC, negative control.

A

Wild BGC-823

NC

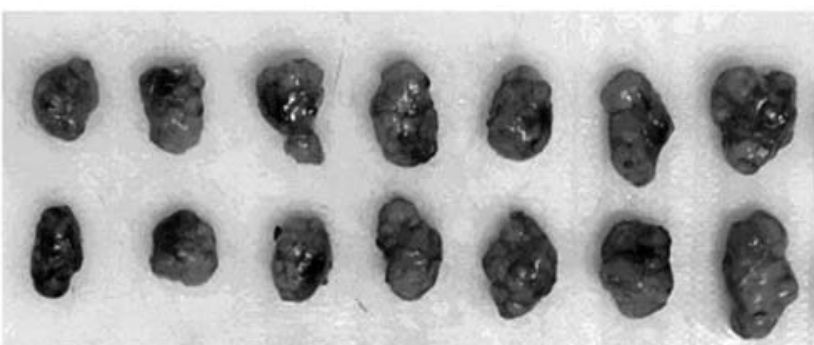

miR-141 mimics

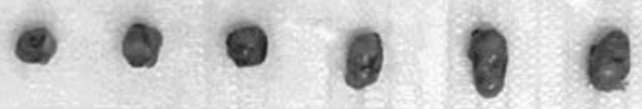

B

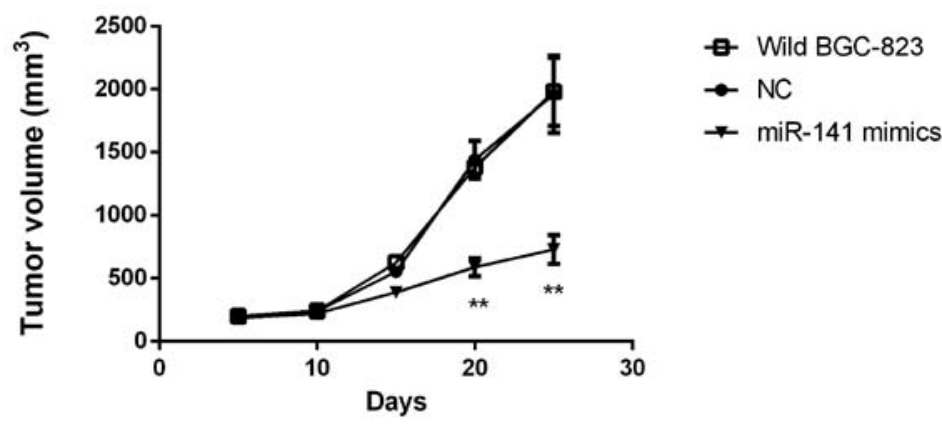

C

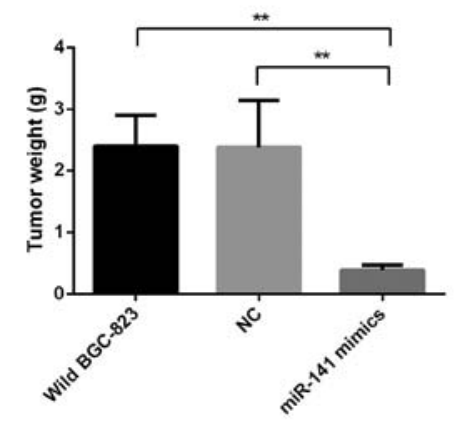

D

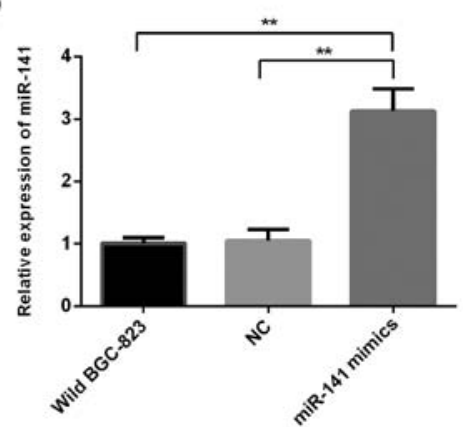

Figure 5. miR-141 suppresses tumorigenicity in vivo. Three groups of mice (n=7/group) were tested. (A) Size of tumors in the three groups. (B) Tumor growth curves of three groups for 4 weeks. (C) Mean tumor weight of three groups at the end of the experiment. (D) Body weight of the animals at the time of sacrifice. Data are presented as the mean \pm standard deviation. ${ }^{* *} \mathrm{P}<0.01$, compared with NC and untransfected BGC-823 groups. miR-141, microRNA-141; NC, negative control. 
cell invasion, migration, proliferation and the maintenance of cancer cell stemness $(33,34)$, which provides clues for the investigation of other miRs, including miR-141. Other miRNAs have also been associated with clinical endpoints and diagnostic potential (35-38). Regardless, there are still a large number of miRNAs which have not been characterized, and which may serve prominent roles in the progression of gastric cancer.

As numerous circulating miRNAs have emerged as biomarkers for cancer diagnosis, miR-141 has also attracted attention. The present study investigated whether circulating miR-141 expression levels were associated with the prognosis and overall survival of patients. It was demonstrated that plasma miR-141 expression levels were significantly lower in patients with gastric cancer compared with in healthy controls, and that this was significantly associated with the survival duration and recurrence rate of patients with gastric cancer. The results suggested that miR-141 may be considered an independent prognostic marker for predicting patient survival, which may also aid the personalized treatment of patients with cancer.

Furthermore, in vitro and in vivo methods were used to investigate the role of miR-141 in the progression and pathophysiology of gastric cancer. miR-141 mimics were successfully transfected into BGC- 823 cells, and the results revealed that overexpression of miR-141 significantly inhibited the proliferation and migration of gastric cancer cells. These results were consistent with the clinical association results of the present study, which are displayed in Tables I and II.

There were a number of limitations to the present study. Firstly, the patient population was small, thus the conclusions regarding the association of miR-141 with clinicopathological characteristics require further verification using a larger patient cohort. Secondly, only one cell line was used for the in vitro study, thus the use of additional gastric cancer cell lines may further support the role of miR-141 in gastric cancer cells. Thirdly, a mechanistic study to determine the target of miR-141, or how miR-141 regulates tumor growth, was not conducted.

In conclusion, to the best of our knowledge, the present study was the first to evaluate the plasma expression levels of miR-141 in patients with gastric cancer from a Chinese population. Although the population size was small, a significant association between the expression of miR-141 and patient survival time was observed. A larger population is required to further confirm the prognostic significance of miR-141 in gastric cancer. Furthermore, the possible molecular targets of miR-141, in addition to its potential interference with signaling pathways, require further investigation.

\section{Acknowledgements}

Not applicable.

\section{Funding}

No funding was received.

\section{Availability of data and materials}

The datasets used and/or analyzed during the current study are available from the corresponding author on reasonable request.

\section{Authors' contributions}

TW and JZ carried out the laboratory experiments. JT and SH collected the clinical information from patients. RW conducted the statistical analysis. LC designed the study and drafted the manuscript.

\section{Ethics approval and consent to participate}

The present study was approved by the Tianjin Nankai Hospital Ethics Committee, and written informed consent was obtained from each subject. All animal experiments were approved by the Ethics Committee of Laboratory Animals of Tianjin Nankai Hospital (approval no. 00000531).

\section{Patient consent for publication}

Written informed consent was obtained from all patients.

\section{Competing interests}

The authors declare that they have no competing interests.

\section{References}

1. Crew KD and Neugut AI: Epidemiology of gastric cancer. World J Gastroenterol 12: 354-362, 2006

2. Song YX, Yue ZY, Wang ZN, Xu YY, Luo Y, Xu HM, Zhang X, Jiang L, Xing CZ and Zhang Y: MicroRNA-148b is frequently down-regulated in gastric cancer and acts as a tumor suppressor by inhibiting cell proliferation. Mol Cancer 10: 1, 2011.

3. Zuberi M, Khan I, Mir R, Gandhi G, Ray PC and Saxena A: Utility of Serum miR-125b as a diagnostic and prognostic indicator and its alliance with a panel of tumor suppressor genes in epithelial ovarian cancer. PLoS One 11: e0153902, 2016.

4. Kinose Y, Sawada K, Nakamura K and Kimura T: The role of microRNAs in ovarian cancer. Biomed Res Int 2014: 249393, 2014.

5. Tilghman SL, Rhodes LV, Bratton MR, Carriere P, Preyan LC, Boue SM, Vasaitis TS, McLachlan JA and Burow ME: Phytoalexins, miRNAs and breast cancer: A review of phytochemical-mediated miRNA regulation in breast cancer. J Health Care Poor Underserved 24 (Suppl 1): S36-S46, 2013.

6. Chen J, Deng S, Zhang S, Chen Z, Wu S, Cai X, Yang X, Guo B and Peng Q: The role of miRNAs in the differentiation of adipose-derived stem cells. Curr Stem Cell Res Ther 9: 268-279, 2014.

7. Du L, Borkowski R, Zhao Z, Ma X, Yu X, Xie XJ and Pertsemlidis A: A high-throughput screen identifies miRNA inhibitors regulating lung cancer cell survival and response to paclitaxel. RNA Biol 10: 1700-1713, 2013.

8. He J, Zhang JF, Yi C, Lv Q, Xie WD, Li JN, Wan G, Cui K, Kung HF, Yang J, et al: miRNA-mediated functional changes through co-regulating function related genes. PLoS One 5: e13558, 2010.

9. Recchiuti A and Serhan CN: Pro-resolving lipid mediators (SPMs) and their actions in regulating miRNA in novel resolution circuits in inflammation. Front Immunol 3: 298, 2012.

10. Wolff LJ, Wolff JA and Sebestyén MG: Effect of tissue-specific promoters and microRNA recognition elements on stability of transgene expression after hydrodynamic naked plasmid DNA delivery. Hum Gene Ther 20: 374-388, 2009.

11. Xia JH, He XP, Bai ZY and Yue GH: Identification and characterization of 63 MicroRNAs in the Asian seabass Lates calcarifer. PLoS One 6: e17537, 2011.

12. Vos S, Vesuna F, Raman V, van Diest PJ and van der Groep P: miRNA expression patterns in normal breast tissue and invasive breast cancers of BRCA1 and BRCA2 germ-line mutation carriers. Oncotarget 6: 32115-32137, 2015.

13. Mushtaq G, Greig NH, Anwar F, Zamzami MA, Choudhry H, Shaik MM, Tamargo IA and Kamal MA: miRNAs as circulating biomarkers for Alzheimer's disease and Parkinson's disease. Med Chem 12: 217-225, 2016. 
14. Ren X, Bai X, Zhang X, Li Z, Tang L, Zhao X, Li Z, Ren Y, Wei S, Wang Q, et al: Quantitative nuclear proteomics identifies that miR-137-mediated EZH2 reduction regulates resveratrol-induced apoptosis of neuroblastoma cells. Mol Cell Proteomics 14: 316-328, 2015.

15. Wang LG, Ni Y, Su BH, Mu XR, Shen HC and Du JJ: MicroRNA-34b functions as a tumor suppressor and acts as a nodal point in the feedback loop with Met. Int J Oncol 42: 957-962, 2013

16. Aure MR, Leivonen SK, Fleischer T, Zhu Q, Overgaard J, Alsner J, Tramm T, Louhimo R, Alnæs GI, Perälä M, et al: Individual and combined effects of DNA methylation and copy number alterations on miRNA expression in breast tumors. Genome Biol 14: R126, 2013

17. Qin W, Zhang K, Clarke K, Weiland T and Sauter ER: Methylation and miRNA effects of resveratrol on mammary tumors vs. Nutr Cancer 66: 270-277, 2014.

18. Schwarzenbach H, Nishida N, Calin GA and Pantel K: Clinical relevance of circulating cell-free microRNAs in cancer. Nat Rev Clin Oncol 11: 145-156, 2014.

19. Xu J, Cao Z, Liu W, You L, Zhou L, Wang C, Lou W, Sun B, Miao Y, Liu X, et al: Plasma miRNAs effectively distinguish patients with pancreatic cancer from controls: A multicenter study. Ann Surg 263: 1173-1179, 2016.

20. Park SM, Gaur AB, Lengyel E and Peter ME: The miR-200 family determines the epithelial phenotype of cancer cells by targeting the E-cadherin repressors ZEB1 and ZEB2. Genes Dev 22: 894-907, 2008

21. Long ZH, Bai ZG, Song JN, Zheng Z, Li J, Zhang J, Cai J, Yao HW, Wang J, Yang YC, et al: miR-141 inhibits proliferation and migration of colorectal cancer SW480 Cells. Anticancer Res 37: 4345-4352, 2017

22. van Jaarsveld MT, Helleman J, Boersma AW, van Kuijk PF, van Ijcken WF, Despierre E, Vergote I, Mathijssen RH, Berns EM, Verweij J, et al: miR-141 regulates KEAP1 and modulates cisplatin sensitivity in ovarian cancer cells. Oncogene 32 4284-4293, 2013.

23. Zhou X, Su J, Zhu L and Zhang G: Helicobacter pylori modulates cisplatin sensitivity in gastric cancer by down-regulating miR-141 expression. Helicobacter 19: 174-181, 2014.

24. Fu WF, Chen WB, Dai L, Yang GP, Jiang ZY, Pan L, Zhao J and Chen G: Inhibition of miR-141 reverses cisplatin resistance in non-small cell lung cancer cells via upregulation of programmed cell death protein 4. Eur Rev Med Pharmacol Sci 20: 2565-2572, 2016.

25. Wang D, Ma J, Ji X, Xu F and Wei Y: miR-141 regulation of EIF4E expression affects docetaxel chemoresistance of non-small cell lung cancer. Oncol Rep 37: 608-616, 2017.

26. Tejero R, Navarro A, Campayo M, Viñolas N, Marrades RM, Cordeiro A, Ruíz-Martínez M, Santasusagna S, Molins L, Ramirez J and Monzó M: miR-141 and miR-200c as markers of overall survival in early stage non-small cell lung cancer adenocarcinoma. PLoS One 9: e101899, 2014.
27. Kim YH, Kim JH, Kim H, Kim H, Lee YC, Lee SK, Shin SK, Park JC, Chung HS, Park JJ, et al: Is the recent WHO histological classification for gastric cancer helpful for application to endoscopic resection? Gastric Cancer 19: 869-875, 2016.

28. Livak KJ and Schmittgen TD: Analysis of relative gene expression data using real-time quantitative PCR and the 2(-Delta Delta C(T)) method. Methods 25: 402-408, 2001.

29. Sen Z, Zhan XK, Jing J, Yi Z and Wanqi Z: Chemosensitizing activities of cyclotides from Clitoria ternatea in paclitaxel-resistant lung cancer cells. Oncol Lett 5: 641-644, 2013.

30. Zhang S, Xin H, Li Y, Zhang D, Shi J, Yang J and Chen X: Skimmin, a coumarin from hydrangea paniculata, slows down the progression of membranous glomerulonephritis by Anti-inflammatory effects and inhibiting immune complex deposition. Evid Based Complement Alternat Med 2013: 819296, 2013.

31. Kontomanolis EN and Koukourakis MI: MicroRNA: The potential regulator of endometrial carcinogenesis. Microrna 4: 18-25, 2015.

32. Fan Y, Zhou Y, Zhou X, Sun F, Gao B, Wan M, Zhou X, Sun J, $\mathrm{Xu}$ X, Cheng L, et al: MicroRNA 224 regulates ion transporter expression in ameloblasts to coordinate enamel mineralization. Mol Cell Biol 35: 2875-2890, 2015.

33. Hu Y, Xu K and Yagüe E: miR-218 targets survivin and regulates resistance to chemotherapeutics in breast cancer. Breast Cancer Res Treat 151: 269-280, 2015.

34. Li Q, Zhu F and Chen P: miR-7 and miR-218 epigenetically control tumor suppressor genes RASSF1A and Claudin-6 by targeting HoxB3 in breast cancer. Biochem Biophys Res Commun 424: 28-33, 2012.

35. Yang L, Xu Q, Xie H, Gu G and Jiang J: Expression of serum miR-218 in hepatocellular carcinoma and its prognostic significance. Clin Transl Oncol 18: 841-847, 2016.

36. Jiang Z, Song Q, Yang S, Zeng R, Li X, Jiang C, Ding W, Zhang J and Zheng Y: Serum microRNA-218 is a potential biomarker for esophageal cancer. Cancer Biomark 15: 381-389, 2015.

37. Xin SY, Feng XS, Zhou LQ, Sun JJ, Gao XL and Yao GL: Reduced expression of circulating microRNA-218 in gastric cancer and correlation with tumor invasion and prognosis. World J Gastroenterol 20: 6906-6911, 2014.

38. Zhang XL, Shi HJ, Wang JP, Tang HS, Wu YB, Fang ZY, Cui SZ and Wang LT: MicroRNA-218 is upregulated in gastric cancer after cytoreductive surgery and hyperthermic intraperitoneal chemotherapy and increases chemosensitivity to cisplatin. World J Gastroenterol 20: 11347-11355, 2014.

This work is licensed under a Creative Commons Attribution-NonCommercial-NoDerivatives 4.0 International (CC BY-NC-ND 4.0) License. 